\title{
An overview of microbial indigo-forming enzymes
}

\author{
Andrea N. Fabara ${ }^{1} \cdot$ Marco W. Fraaije ${ }^{1}$
}

Received: 11 October 2019 /Revised: 23 November 2019 / Accepted: 28 November 2019 / Published online: 13 December 2019

(C) The Author(s) 2019

\begin{abstract}
Indigo is one of the oldest textile dyes and was originally prepared from plant material. Nowadays, indigo is chemically synthesized at a large scale to satisfy the demand for dyeing jeans. The current indigo production processes are based on fossil feedstocks; therefore, it is highly attractive to develop a more sustainable and environmentally friendly biotechnological process for the production of this popular dye. In the past decades, a number of natural and engineered enzymes have been identified that can be used for the synthesis of indigo. This mini-review provides an overview of the various microbial enzymes which are able to produce indigo and discusses the advantages and disadvantages of each biocatalytic system.
\end{abstract}

Keywords Indigo $\cdot$ Indole $\cdot$ Naphthalene dioxygenase $\cdot$ Styrene monoxygenase $\cdot$ P450 monoxygenase $\cdot$ Peroxygenase $\cdot$ Flavoprotein monooxygenase

\section{Introduction}

Humans have decorated textiles with dyes and pigments, often derived from plant material, since ancient times (Aino et al. 2018). Indigo blue (in short: indigo) is one of the oldest dyes to be used for textile dyeing (Fig. 1). In 2009 at Huaca Prieta, Peru, the oldest indigo-dyed cotton fabric was discovered, dating back to 6000 years ago (Splitstoser et al. 2016). Indigo-dying was also known in ancient Egypt; the funerary wardrobe of Tutankhamun included an indigo-dyed state robe. Clearly, the use of indigo as dye was widespread already early in human history (Clark et al. 1993).

Traditionally, indigo has been prepared from various plants. This is done by fermenting plant material, which will liberate indoxyl from indigo precursors, typically glycosylated forms of indoxyl such as indican and isatan B (Fig. 1). Through air-mediated oxidation, indoxyl then spontaneously dimerizes to form indigo. To dye textiles, indigo is first chemically reduced which results in the soluble reduced form of indigo, leucoindigo. The indigo-dying process, in which indigo is chemically treated, was traditionally done in buckets or

Marco W. Fraaije

m.w.fraaije@ rug.nl

1 Molecular Enzymology group, University of Groningen, Nijenborgh 4, 9747 AG Groningen, The Netherlands vats, hence the classification as a vat-dye. The deposition of the insoluble indigo on the fabric results in a special decoration of the fabric material as the fabric is not penetrated by the dye. This gives denim and other indigo-dyed garments their special appearance, where wear or abrasion exposes the white interior of the fiber.

The most effective plant-based process of producing the indigo dye involved the plant Indigofera tinctoria, which is distributed throughout the tropical and subtropical regions of the world and particularly in India. In fact, the Greeks referred to the dye as "indikon" which means "from India." Yet, also in more moderate climate regions, indigo has been produced and used from alternative plants. In Europe, woad (Isatis tinctoria) was traditionally used as the source of indigo. In fact, for centuries, there were many regions where woad cultivation and processing was a dominant industry. However, through increasing trade between Europe and other continents, the import of indigo from India fully eradicated woad-based industries starting in the 16th century. While Indigofera contains relatively high concentration of indican, woad contains significantly lower amounts of two indigo precursors: indican and isatan B (Fig. 1) (Gilbert et al. 2004).

At the advent of the 20th century, a petroleum-based chemical process to synthesize indigo was introduced. This rapidly evolved into an effective industrial process and replaced most of the plant-based production of indigo. 
Fig. 1 Structural formulas of indigo, indoxyl, and some of its plant precursors, indican and isatan B

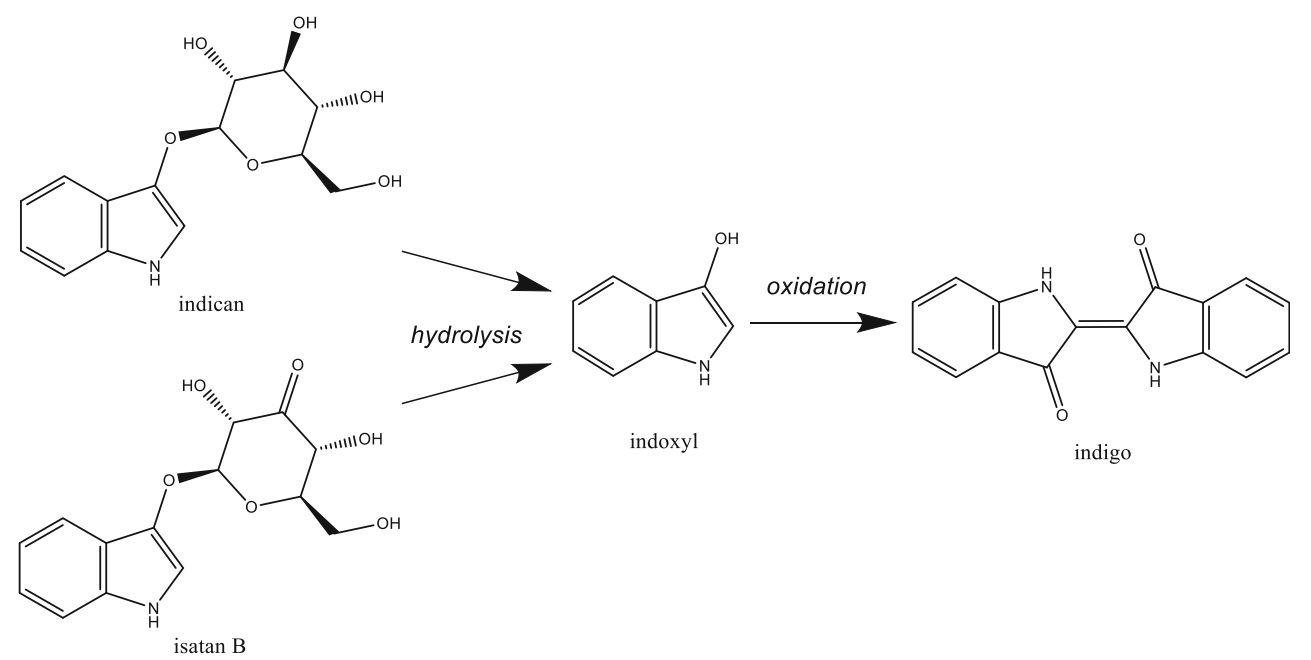

\section{Chemical production of indigo}

About 150 years ago, Adolf von Baeyer succeeded in elucidating the structural formula of indigo. He was also the first in developing a method for the chemical synthesis of indigo; in 1870 , he described the synthesis of indigo starting from isatin. In subsequent years, Baeyer and others developed alternative synthetic routes for the synthesis of indigo, but most of them started from expensive starting material and were not commercially viable. Yet, within a few decades, several effective indigo production processes were developed (Scheme 1), and indigo production at tonne scale was established. Industrial production of indigo started around 1900 and developed into the current large scale industrial processes, replacing virtually all former plant-based production sites. Current large scale production processes typically rely on aniline as a cheap fossil-based feedstock.

\section{Alternative indigo production processes}

Indigo has been the world's most important and popular dyestuff, and the demand is still increasing, especially in the denim industry. Plant material, mainly leaves, contains indican as a colorless compound. By fermentation, indican is hydrolysed into $\beta$-D-glucose and indoxyl, while in a next step, using air as oxidant, indigo is obtained as solid material (Fig. 1). Current chemical production processes do not start from renewable material but instead depend on relatively cheap petrochemical precursors. The chemistry used for the industrial production of indigo is quite harsh, not environmentally friendly, and leads to problems in the disposal of the dye waste. Because these factors are not priced in, this is a commercially viable process. To prevent the formation of large waste streams and to be able to use a renewable feedstock, it is desirable to develop a more sustainable process. For this, biotechnological approaches are being explored.

Indigo production based on plant material, reviving and optimizing the traditional plant-based processes, could be an option. This would involve the breeding of plants with high indican content and other beneficial traits. Recently, obtained genetic insights in the natural indigo synthesis pathway in plants could be exploited for this (Jin et al. 2016; Inoue et al. 2017), and it has already been shown that through genetic engineering, plants can be bred that produce various indigo dyes (Fräbel et al. 2018). However, production of indigo using plants would compete with food and feed production.

As an alternative and promising approach, the production of indigo by fermentation has been explored since the early 1980's when the first bacterial strains capable of indigo synthesis were identified. Among the discovered microbial indigo producers, the majority are aromatic hydrocarbon-degrading bacteria (Bhushan et al. 2000). Although various bacterial strains and enzymes have been identified to be able to produce indigo, there is still no large-scale industrial biotechnological process for producing indigo.

With the current realization that production processes should be (more) sustainable, the demand for a biotechnological indigo production process becomes more urgent, and modern techniques for enzyme and strain engineering make it more feasible. In the next paragraphs, details of the microbial enzymes known to form indigo are discussed. In all cases,
Scheme 1 Timeline of indigo production processes

\begin{tabular}{lccccc}
\hline indigo derived from various plants & $\vdots$ & $\begin{array}{c}\text { indigo produced } \\
\text { from Indigofera }\end{array}$ & $\begin{array}{c}\text { synthetic } \\
\text { indigo }\end{array}$ & $\begin{array}{l}\text { biotech } \\
\text { indigo }\end{array}$ \\
\hline $4000 \mathrm{BC}$ & $1500 \mathrm{AD}$ & & $1900 \mathrm{AD}$ & $2030 \mathrm{AD}$ ?
\end{tabular}


these enzymes oxidize indole to form indoxyl, which spontaneously dimerizes into indigo. Besides naturally occurring enzymes, enzymes engineered towards indigo production will also be discussed.

\section{Microbial enzymes producing indigo}

In the last few decades, a large number of indigo-producing enzymes have been identified in microorganisms, mainly in bacteria. In the past, indigo production was observed when studying a particular bacterial strain, and in recent years, a number of indigo-producing enzymes were discovered through metagenome mining ( $\mathrm{Lim}$ et al. 2005; van Hellemond et al. 2007; Singleton et al. 2012; Nagayama et al. 2015; Ma et al. 2018). The discovery of such enzymes was often a serendipitous finding, based on the pink or bluish appearance of colonies or cultures. All these enzymes convert indole through an oxygenation reaction. In most cases, this is catalyzed by using electron donating cofactors and molecular oxygen, but also peroxide-driven peroxygenases have been shown to convert indole into indigo. The identified redox enzymes can be dissected into three different enzyme classes based on the cofactor used by the enzymes to perform the oxygenation of indole: non-heme iron oxygenases, heme-containing oxygenases, and flavin-dependent monooxygenases.

\section{Non-heme iron oxygenases}

\section{Naphthalene dioxygenases}

The realization that microbial enzymes can be used for indigo production started in 1983 when studying naphthalene dioxygenase-encoding genes from Pseudomonas putida G7. The corresponding multi-component naphthalene dioxygenase (NDO) system was expressed in Escherichia coli resulting in blue-colored cultures (Ensley et al. 1983). Indigo production could be boosted by adding tryptophan or indole to the medium. This suggested that the oxygenase was capable to convert indole into indoxyl, leading to indigo formation. Yet, the initial (labile) product of action of NDO is indoline-2,3diol which quickly decays to form indoxyl, which subsequently condenses into indigo (route A in Fig. 2).

NDO (EC 1.14.13.8) has a broad substrate range and catalyzes several types of reactions including cis-dihydroxylation, monooxygenation, and desaturation reactions (Parales et al. 2000). Building on this finding, through a combination of tuning expression levels, protein engineering, and optimizing medium composition, it was shown that a recombinant $E$. coli could be used to produce indigo from glucose (Murdock et al. 1993). While the productivity $(135 \mathrm{mg} / \mathrm{L})$ was still modest, this demonstrated that a fermentative approach can be effective. Since then, many other aromatic hydrocarbon-degrading bacteria have been identified and studied for their capability to produce indigo, often with indole as precursor (O'Connor and Hartmans 1998; Bhushan et al. 2000; Alemayehu et al. 2004; Pathak and Madamwar 2010; Qu et al. 2012b). While many of these bacteria are pseudomonads, other bacteria have also been found to harbor NDOs that can be used to produce indigo (Mercadal et al. 2010; Qu et al. 2010).

NDO is a multi-component enzyme system that allows the respective organism to hydroxylate naphthalene and related compounds to facilitate full metabolism of such aromatic compounds. Besides the oxygenase enzyme component, it also involves a flavin-dependent reductase and a ferredoxin component to generate the electrons required by the oxygenase. Details on how NDO performs catalysis were revealed when its crystal structure was elucidated (Kauppi et al. 1998). The oxygenase forms an $\alpha_{3} \beta_{3}$ heterohexameric structure composed of two different subunits, the $\alpha$ - and $\beta$-subunits. The active site resides in the $\alpha$-subunits and contains a non-heme iron cofactor. The iron is liganded by two histidines and an aspartate. The active site is rather buried, connected with a tunnel to the protein surface for substrate/product diffusion. Electrons from ferredoxin are delivered to the iron via a Rieske $[2 \mathrm{Fe}-2 \mathrm{~S}]$ center located in the neighboring $\alpha$-subunit at a distance of $12 \AA$. The tunnel and shape of the active site
Fig. 2 Different enzymatic routes towards indigo, either via dioxygenation (A), direct hydroxylation to indoxyl (B), or via epoxidation $(\mathrm{C})$

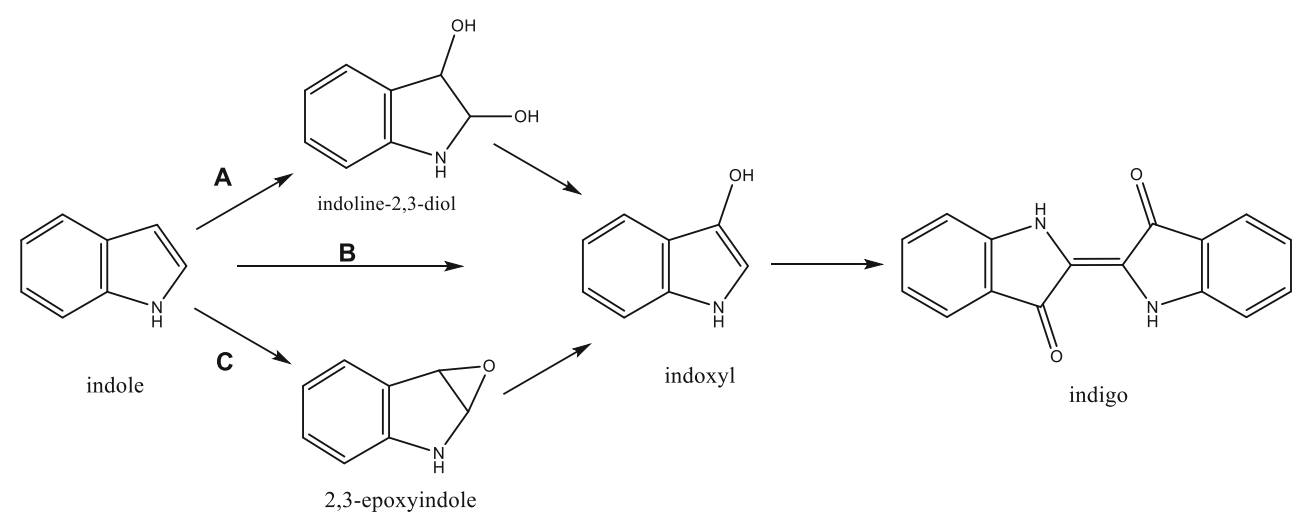


determine the substrate specificity of NDO and sequencerelated oxygenases. A number of NDO homologs have been identified that are similar in sequence but vary significantly in substrate scope. These include toluene dioxygenases, cumene dioxygenases, and biphenyl dioxygenases (Groeneveld et al. 2016). Overlap of substrate profiles has been observed as some cumene, and toluene dioxygenases were shown to produce indigo from indole (Stephens et al. 1989; Woo et al. 2000; Groeneveld et al. 2016).

Recombinant $E$. coli strains expressing NDO have been reported to produce $36-300 \mathrm{mg}$ indigo per liter of culture broth. These studies have shown that for an optimal production of indigo, tuning of expression and growth conditions is crucial. Besides for adding tryptophan, indole and/or glucose and other medium components can also affect productivity. The addition of iron to the medium was suggested to boost the functioning of the coexpressed ferredoxin (Murdock et al. 1993). This also hints to the complexity of the NDO system for functional expression, 4 genes need to be coexpressed. With multiple enzyme components and the requirement of incorporation of $\mathrm{Fe}$ $\mathrm{S}$ clusters and a catalytic iron, the NDO system may not be the ideal biocatalytic tool.

\section{Multicomponent phenol hydroxylases}

Another multi-component enzyme class that was shown to be capable to produce indigo are the bacterial multicomponent phenol hydroxylases (mPHs) (EC 1.14.13.7). mPHs consist of a hexameric hydroxylase component composed of three different subunits $(\alpha \beta \gamma)_{2}$ : a flavoprotein reductase to generate and deliver electron to the oxygenase component and a cofactorless regulatory protein (Nordlund et al. 1990; Leahy et al. 2003). For catalysis, the $\alpha$-oxygenase subunit contains a carboxylate-bridged diiron center. The mPHs share features with the soluble methane monooxygenases. Being effective in mono-hydroxylating phenol, it is likely that indigo formation is achieved through hydroxylation of indole into indoxyl (route B in Fig. 2). A related multicomponent diiron enzyme system has also been reported to be able to produce indigo, toluene-4-monooxygenase (Yen et al. 1991). Engineering of this bacterial monooxygenase resulted in mutants with different regioselectivities when hydroxylating indole, thereby producing different indigoids (McClay et al. 2005). Only a few reports on the use of $\mathrm{mPHs}$ for indigo production have appeared (Qu et al. 2012a). This may partly be due to the fact that these types of oxygenases have been discovered quite recently. The reported studies on using $\mathrm{mPH}$-harboring microbes for indigo production suggest that these multicomponent enzymes can indeed be used in recombinant hosts. Expression in E. coli led to a production of $52 \mathrm{mg}$ indigo per liter of medium (Doukyu et al. 2003). However, it is worth noting that the original strain from which the genes were cloned, Acinetobacter sp. ST-550, reached higher titers of indigo (292 mg/L) (Doukyu et al. 2002). Similar to the NDOs, it may be challenging to find optimal conditions for functional and stable expression of all components of a $\mathrm{mPH}$ in a recombinant host.

\section{Heme-containing oxygenases}

\section{Cytochrome P450 monooxygenases}

Cytochrome P450 monooxygenases (CYPs) (EC 1.14.14.X) contain a heme as redox cofactor, enabling catalysis of various oxidation reactions. A plethora of CYPs exist in nature with highly diverse physiological roles. Microbes often employ CYPs in catabolic pathways. A thoroughly studied CYP is the P450 BM3 (CYP102A1), a fatty acid hydroxylating CYP from Bacillus megaterium ATCC 14581. This CYP is attractive as biocatalyst because it contains a flavin-containing reductase domain in addition to the typical $\mathrm{P} 450$ monooxygenase domain. The reductase domain renders the CYP self-sufficient; it does not rely on a secondary reductase but merely requires NADPH to function. Furthermore, P450 BM3 can be easily expressed in E. coli and is rather stable. The wild-type enzyme is not capable to convert indole. Yet, in 2000 , directed evolution of P450 BM3 accidentally resulted in mutant enzymes that produced indigo ( $\mathrm{Li}$ et al. 2000). By introducing three mutations, a variant was created which displays a high activity on indole $\left(k_{\text {cat }}=2.7 \mathrm{~s}^{-1}(\mathrm{Li}\right.$ et al. 2000a) $)$. Around the same time, it was discovered that also some human CYPs convert indole into indigo (Gillam et al. 1999; Gillam et al. 2000; Banoglu et al. 2001). Conversion by CYPs was found to proceed via formation of indoxyl (Gillam et al. 2000) (route B in Fig. 2). However, as eukaryotic CYPs are typically rather slow in catalysis, human or other mammalian CYPs are enzymes not suitable for a biotechnological process. For this, engineered variants of $\mathrm{P} 450$ BM3 or other microbial CYPs are more suitable. A recent study has demonstrated that the performance on indole of the above-mentioned triple mutant of P450 BM3 could be improved by one order of magnitude through directed evolution. The improvement was brought about by merely adding one more mutation. Moreover, in the last two decades, more microbial CYPs have been reported for their capacity of indigo formation (Brixius-Anderko et al. 2017; Fiorentini et al. 2018; Kim et al. 2018) which may also represent good starting points for creating an optimized CYP for indigo production. The feature that conversion of indole into indigo can be seen by eye makes it attractive to apply directed evolution protocols. Such colorimetric detection allows to screen large mutant enzyme libraries. 


\section{Unspecific peroxygenases}

The oxygenases described above all depend on reduced coenzymes, such as NADH and NADPH, as electron donors. One class of enzymes that would eliminate such cofactor dependency is the unspecific peroxygenases (UPOs) (EC 1.11.2.1). These redox enzymes are capable of oxygenations with the help of hydrogen peroxide. Similar to CYPs, UPOs contain a tightly bound heme cofactor that catalyzes the oxygenations. However, in UPOs, the required oxygen and electrons for an oxygenation reaction are delivered indirectly, by using hydrogen peroxide as substrate. Recently, it was described in a patent that an UPO can convert indole into indigo (Kalum et al. 2014; Martínez et al. 2017) by using hydrogen peroxide as oxidant. Besides for indole, the studied fungal peroxygenase can also be used for the preparation of other indigoids. The reaction proceeds via formation of 2,3-epoxyindole as intermediate product (route $\mathrm{C}$ in Fig. 2). This rearranges spontaneously into indoxyl but also the side-product 2-oxindole is formed. This mixture of products prevents full conversion of indole into indigo. So far, UPOs have only been identified in fungi (Faiza et al. 2019). The recombinant production of UPOs has been found to be problematic which has hampered thorough biochemical investigations, enzyme engineering studies, and applications of these redox enzymes. Effective expression systems will need to be developed before UPOs can be considered for large scale industrial processes. Another weakness of UPOs is that they can easily become inactivated by hydrogen peroxide. Careful dosing of hydrogen peroxide is required for optimal usage of the biocatalyst. Enzyme engineering may also help in generating variants that are less sensitive towards inactivation.

Other heme-containing enzymes might offer another approach in developing peroxygenases for indigo production. It has been reported that the marine dehaloperoxidasehemoglobin from Amphitrite ornata and the mammalian heme-containing indoleamine 2,3-dioxygenase can act as peroxygenases when offered indoles and hydrogen peroxide (Kuo and Mauk 2012; Barrios et al. 2014). However, it seems that these enzymes are rather slow and also generate other indole-based products. Moreover, their mammalian origin makes them hard to use in microbial fermentations. Inspired by the catalytic power of heme-dependent enzymes, chemical approaches are also explored in which bio-inspired catalysts are designed, based on the iron-porphyrin structure of heme cofactors (Rebelo et al. 2014). This is a new approach to produce indigo based on a simple and cost-effective model system of the enzymes. The method considers the oxidation of indole by hydrogen peroxide by using an iron(III)porphyrin in ethanol as solvent. The yields of indigo depend on the type of metalloporphyrin system used and on the control of the oxidation conditions.

\section{Flavin-dependent monooxygenases}

Several flavin-dependent monooxygenases have been reported to be able to produce indigo from indole. All these indigoproducing enzymes belong to four distinct flavoprotein monooxygenase classes (van Berkel et al. 2006) and are discussed below.

\section{Styrene/indole monooxygenases}

The FAD-dependent styrene monooxygenases (EC 1.14.14.11), belonging to the class $\mathrm{E}$ flavoprotein monooxygenases (van Berkel et al. 2006), are twocomponent systems which rely on a flavin reductase and a monooxygenase. In most cases, these two components are encoded by separate genes, but in a few cases, the components are fused (van Hellemond et al. 2007; Tischler et al. 2009). The reductase uses NADH to generate reduced FAD, which subsequently has to find the monooxygenase by diffusion. The monooxygenase is able to form a reactive peroxyflavin intermediate upon binding reduced FAD by reacting with dioxygen, which subsequently can react with styrene. Styrene monooxygenases are typically highly enantioselective, which makes them attractive biocatalysts. Styrene monooxygenases represent also one of the few flavoprotein monooxygenases capable of performing epoxidations. Most of the reported styrene monooxygenases are involved in degrading styrene, and their activity on indole can be regarded as a the result of a relaxed substrate specificity (O'Connor et al. 1997; Panke et al. 1998; van Hellemond et al. 2007). In fact, it was shown that indole is indeed converted into the corresponding epoxide before indoxyl and indigo is formed (Heine et al. 2019) (route C in Fig. 2). Furthermore, based on sequence analysis and biochemical data, "styrene monooxygenases" can be dissected into two groups: styrene monooxygenases and indole monooxygenases (Heine et al. 2018). While the true styrene monooxygenases act on styrene, the indole monooxygenases have evolved to take part in indole degradation. As these indole monooxygenases have only been recognized very recently, more studies are needed to reveal their potential as biocatalysts for indigo production. Some styrene monooxygenases have already been explored for producing indigo. A recent study aimed at optimizing indigo production by expressing styrene monooxygenase in Pseudomonas putida. This resulted in $52 \mathrm{mg}$ of indigo per liter of culture (Cheng et al. 2016). Progress in using styrene or indole monooxygenases for the production of indigo may benefit from previous efforts to optimize the fermentative production of ( $S$ )-styrene oxide using styrene monooxygenase (Park et al. 2006; Kuhn et al. 2012). 


\section{2-Hydroxybiphenyl 3-monooxygenase}

Another FAD-dependent monooxygenase, for which indigo formation has been shown, is a laboratory-evolved mutant of 2-hydroxybiphenyl 3-monooxygenase (EC 1.14.13.44) (Meyer et al. 2002). This flavoprotein monooxygenase does not depend on a reductase; it is a single component monooxygenases which is fuelled by NADPH, belonging to the class A flavoprotein monooxygenases (van Berkel et al. 2006). During a directed evolution campaign, a mutant enzyme was identified that rendered the respective culture a dark blue color. For this engineered flavoprotein monooxygenase, it was found that indigo formation was preceded by hydroxylation of indole. Except for 3-hydroxylation of indole, resulting in indoxyl, some 2-hydroxylation also occurred, resulting in 2-oxindole. As a result, formation of some indirubin was also observed. Though a large number of class A flavoprotein monooxygenases have been reported, all acting on aromatic substrates, so far only the engineered 2-hydroxybiphenyl 3-hydroxylase was reported to act on indole to produce indigoids. As a result, relatively little data is available on such indigo-forming hydroxylases. Still, the engineered FAD-containing hydroxylase was shown to be quite productive when using recombinant $E$. coli cells, outperforming the indigo production of $E$. coli expressing naphthalene dioxygenase (Ensley et al. 1983; Meyer et al. 2002).

\section{Flavin-containing monooxygenases and Baeyer-Villiger monooxygenases}

Another major class of FAD-containing monooxygenases, the class B flavoprotein monooxygenases (EC 1.14.13.X), has been shown to be rather rich in enzymes capable of oxidizing indole. The most prominent examples are bacterial flavincontaining monooxygenases (FMOs) (Choi et al. 2003; Singh et al. 2010; Ameria et al. 2015; Lončar et al. 2019). The first FMO efficient in indigo production was described in 2003 and was obtained from a marine bacterium, Methylophaga aminisulfidivorans (Choi et al. 2003). Biochemical characterization of this bacterial FMO showed that it is a dimeric and soluble enzyme which relies on NADPH and dioxygen for activity (Alfieri et al. 2008). While the enzyme is most efficient with small aliphatic amines and sulphides, it also accepts indole as substrate. It is also capable to convert indole derivatives into indigoid dyes (Rioz-Martínez et al. 2011). Through optimizing a fermentation process, using $E$. coli as recombinant expression host, an impressive indigo yield of $911 \mathrm{mg} / \mathrm{L}$ was achieved (Han et al. 2011). In the past few years, some other sequence-related indigo-producing bacterial FMOs have also been described (Ameria et al. 2015; Kim et al. 2017; Lončar et al. 2019); for the FMO from Corynebacterium glutamicum, high yields of indigo when using recombinant $E$. coli cells were reported $(685 \mathrm{mg} / \mathrm{L})$. The studied FMOs display exceptional high indigo productivities, making them attractive biocatalysts for the biotechnological production of this vat dye. Except for focusing on the production of indigo, a recent study has shown that FMOs can also be used for the production of indican. Coexpression of bacterial FMO together with a glucosyltransferase from the indigo plant Polygonum tinctorium was established in $E$. coli which resulted in the production of indican $(2.9 \mathrm{~g} / \mathrm{L})$ (Hsu et al. 2018). This protected form of indoxyl represents a convenient precursor of indigo.

A subclass of class B flavoprotein monooxygenases are the type I Baeyer-Villiger monooxygenases. These FADcontaining and NADPH-dependent monooxygenases have similar structural features that also translate into a similar catalytic mechanism when compared with FMOs. However, Baeyer-Villiger monooxygenases (BVMOs) have some specific features in their active sites that allow them to perform Baeyer-Villiger oxidations (Orru et al. 2011). Yet, they also were shown to be capable to catalyze other oxidation reactions, such as sulfoxidations, epoxidations, and $\mathrm{N}$-oxidations. Though no wild-type BVMO has been shown to be capable of converting indole into indigo, an engineered BVMO was discovered that could be used for indigo production, the M446G phenylacetone monooxygenase mutant (Pazmiño et al. 2007). The mutant was prepared in a successful attempt to broaden the substrate scope of this bacterial and thermostable BVMO.

\section{Alternative two-component flavoprotein monooxygenases}

Studies have appeared in literature that indicate that also another group of flavoprotein monooxygenases can produce indigo, various class $\mathrm{D}$ flavoprotein monooxygenases were shown to be involved in indigo formation (Hart et al. 1990; Kosono et al. 1997; Drewlo et al. 2001; Choi et al. 2004; Alemayehu et al. 2004; Lim et al. 2005; Leveau and Gerards 2008; Lin et al. 2012; Sadauskas et al. 2017; Dai et al. 2019). All these reports involve sequence-related two-component systems in which a flavin reductase generates the reduced flavin cofactor which is subsequently used by the indole oxygenase component. No detailed studies have been carried out on these indole oxygenases. Based on sequence homology, they probably operate similar to the FAD-utilizing 4hydroxyphenylacetate 3-hydroxylase (Thotsaporn et al. 2011). The cofactor requirement of class D flavoprotein monooxygenases (Heine et al. 2018) is variable (they are either FMN- or FAD-dependent) and still has to be determined for the described indole oxygenases. Most of these indole oxygenases have been studied in view of their role in bacterial indole degradation. Only in a recent study the potential of using such a two-component system for indigo production 
was demonstrated. Expression of the indole oxygenase system from Cupriavidis sp. SHE in E. coli and optimization of the medium for indigo production yielded in $307 \mathrm{mg}$ indigo per liter of culture broth (Dai et al. 2019).

\section{Conclusions and perspectives}

This review provides an overview of all enzyme types that have been shown to be able to produce indigo. After several decades of research on microbial or enzymatic indigo production, it becomes clear that a variety of redox enzymes can oxidize indole into indigo. It depends on the type of enzyme what initial oxidized product is formed, and whether side products are formed. While a number of indigo-forming oxygenases are part of a multi-component system, selfsufficient oxygenases have also been discovered or engineered. Reported productivities for indigo vary greatly and may hint to enzymes that are more suitable for indigo production. Yet, the set-up and conditions for indigo production vary enormously among studies which makes a fair comparison difficult. Future studies will resolve which enzyme system(s) are best suited for a biotechnological production of indigo.

Funding information A.N.F. received funding from the European Union Horizon 2020 Programme under grant agreement No. 722390, the ITNOXYTRAIN project.

\section{Compliance with ethical standards}

Conflict of interest The authors declare that they have has no conflict of interest.

Ethical approval This article does not contain any studies with human participants or animals performed by any of the authors.

Open Access This article is licensed under a Creative Commons Attribution 4.0 International License, which permits use, sharing, adaptation, distribution and reproduction in any medium or format, as long as you give appropriate credit to the original author(s) and the source, provide a link to the Creative Commons licence, and indicate if changes were made. The images or other third party material in this article are included in the article's Creative Commons licence, unless indicated otherwise in a credit line to the material. If material is not included in the article's Creative Commons licence and your intended use is not permitted by statutory regulation or exceeds the permitted use, you will need to obtain permission directly from the copyright holder. To view a copy of this licence, visit http://creativecommons.org/licenses/by/4.0/.

\section{References}

Aino K, Hirota K, Okamoto T, Tu Z, Matsuyama H, Yumoto I (2018) Microbial communities associated with indigo fermentation that thrive in anaerobic alkaline environments. Front Microbiol 9:2196
Alemayehu D, Gordon LM, O’Mahony MM, O’Leary ND, Dobson ADW (2004) Cloning and functional analysis by gene disruption of a novel gene involved in indigo production and fluoranthene metabolism in Pseudomonas alcaligenes PA-10. FEMS Microbiol Lett 239:285-293

Alfieri A, Malito E, Orru R, Fraaije MW, Mattevi A (2008) Revealing the moonlighting role of NADP in the structure of a flavin-containing monooxygenase. Proc Natl Acad Sci U S A 105:6572-6577

Ameria SPL, Jung HS, Kim HS, Han SS, Kim HS, Lee JH (2015) Characterization of a flavin-containing monooxygenase from Corynebacterium glutamicum and its application to production of indigo and indirubin. Biotechnol Lett 37:1637-1644

Banoglu E, Jha GG, King RS (2001) Hepatic microsomal metabolism of indole to indoxyl, a precursor of indoxyl sulfate. Eur J Drug Metab Pharmacokinet 26:235-240

Barrios DA, D'Antonio J, McCombs NL, Zhao J, Franzen S, Schmidt AC, Sombers LA, Ghiladi RA (2014) Peroxygenase and oxidase activities of dehaloperoxidase-hemoglobin from Amphitrite ornata. J Am Chem Soc 136:7914-7925

Bhushan B, Samanta SK, Jain RK (2000) Indigo production by naphthalene-degrading bacteria. Lett Appl Microbiol 3:5-9

Brixius-Anderko S, Hannemann F, Ringle M, Khatri Y, Bernhardt R (2017) An indole-deficient Escherichia coli strain improves screening of cytochromes $\mathrm{P} 450$ for biotechnological applications. Biotechnol Appl Biochem 64:315-326

Cheng L, Yin S, Chen M, Sun B, Hao S, Wang C (2016) Enhancing indigo production by over-expression of the styrene monooxygenase in Pseudomonas putida. Curr Microbiol 73:248254

Choi HS, Kim JK, Cho EH, Kim YC, Kim JI, Kim SW (2003) A novel flavin-containing monooxygenase from Methylophaga $s p$ strain SK1 and its indigo synthesis in Escherichia coli. Biochem Biophys Res Commun 306:930-936

Choi KY, Kim D, Koh S-C, So J-S, Kim J-S, Kim E (2004) Molecular cloning and identification of a novel oxygenase gene specifically induced during the growth of Rhodococcus $s p$. strain T104 on limonene. J Microbiol 42:160-162

Clark RJH, Cooksey CJ, Daniels MAM, Withnall R (1993) Indigo, woad, and tyrian purple: important vat dyes from antiquity to the present. Endeavour 17:191-199

Dai C, Ma Q, Li Y, Zhou D, Yang B, Qu Y (2019) Application of an efficient indole oxygenase system from Cupriavidus sp. SHE for indigo production, Bioprocess Biosyst Eng

Doukyu N, Nakano T, Okuyama Y, Aono R (2002) Isolation of an Acinetobacter $s p$. ST-550 which produces a high level of indigo in a water-organic solvent two-phase system containing high levels of indole. Appl Microbiol Biotechnol 58:543-546

Doukyu N, Toyoda K, Aono R (2003) Indigo production by Escherichia coli carrying the phenol hydroxylase gene from Acinetobacter $s p$ strain ST-550 in a water-organic solvent two-phase system. Appl Microbiol Biotechnol 60:720-725

Drewlo S, Brämer CO, Madkour M, Mayer F, Steinbüchel A (2001) Cloning and expression of a Ralstonia eutropha HF39 gene mediating indigo formation in Escherichia coli. Appl Environ Microbiol 67:1964-1969

Ensley BD, Ratzkin BJ, Osslund TD, Simon MJ, Wackett LP, Gibson DT (1983) Expression of naphthalene oxidation genes in Escherichia coli results in the biosynthesis of indigo. Science 222:167-169

Faiza M, Huang S, Lan D, Wang Y (2019) New insights on unspecific peroxygenases: superfamily reclassification and evolution. BMC Evol Biol 19:76

Fiorentini F, Hatzl A-M, Schmidt S, Savino S, Glieder A, Mattevi A (2018) The extreme structural plasticity in the CYP153 subfamily of P450s directs development of designer hydroxylases. Biochemistry 57:6701-6714 
Fräbel S, Wagner B, Krischke M, Schmidts V, Thiele CM, Staniek A, Warzecha H (2018) Engineering of new-to-nature halogenated indigo precursors in plants. Metab Eng 46:20-27

Gilbert KG, Maule HG, Rudolph B, Lewis M, Vandenburg H, Sales E, Tozzi S, Cooke DT (2004) Quantitative analysis of indigo and indigo precursors in leaves of Isatis spp. and Polygonum tinctorium. Biotechnol Prog 20:1289-1292

Gillam EM, Aguinaldo AM, Notley LM, Kim D, Mundkowski RG, Volkov AA, Arnold FH, Soucek P, DeVoss JJ, Guengerich FP (1999) Formation of indigo by recombinant mammalian cytochrome P450. Biochem Biophys Res Commun 265:469-472

Gillam EM, Notley LM, Cai H, De Voss JJ, Guengerich FP (2000) Oxidation of indole by cytochrome P450 enzymes. Biochemistry 39:13817-13824

Groeneveld M, van Beek HL, Duetz WA, Fraaije MW (2016) Identification of a novel oxygenase capable of regiospecific hydroxylation of D-limonene into (+)-trans-carveol. Tetrahedron 72:72637267

Han GH, Bang SE, Babu BK, Chang M, Shin HJ, Kim SW (2011) Bioindigo production in two different fermentation systems using recombinant Escherichia coli cells harboring a flavin-containing monooxygenase gene (fmo). Process Biochem 46:788-791

Hart S, Kirby R, Woods DR (1990) Structure of a Rhodococcus gene encoding pigment production in Escherichia coli. J Gen Microbiol 136:1357-1363

Heine T, Großmann C, Hofmann S, Tischler D (2019) Indigoid dyes by group E monooxygenases: mechanism and biocatalysis. Biol Chem 400:939-950

Heine T, van Berkel WJH, Gassner G, van Pée K-H, Tischler D (2018) Two-component FAD-dependent monooxygenases: current knowledge and biotechnological opportunities. Biology (Basel) 7(3):42

Hsu TM, Welner DH, Russ ZN, Cervantes B, Prathuri RL, Adams PD, Dueber JE (2018) Employing a biochemical protecting group for a sustainable indigo dyeing strategy. Nat Chem Biol 14:256-261

Inoue S, Moriya T, Morita R, Kuwata K, Thul ST, Sarangi BK, Minami Y (2017) Characterization of UDP-glucosyltransferase from Indigofera tinctoria. Plant Physiol Biochem 121:226-233

Jin Z, Kim J-H, Park SU, Kim S-U (2016) Cloning and characterization of indole synthase (INS) and a putative tryptophan synthase $\alpha$ subunit (TSA) genes from Polygonum tinctorium. Plant Cell Rep 35:2449-2459

Kalum L, Lund H, Hofrichter M, Ullrich R (2014) Enzymatic preparation of indigo dyes and intermediates. WO2014122109A1 patent

Kauppi B, Lee K, Carredano E, Parales RE, Gibson DT, Eklund H, Ramaswamy S (1998) Structure of an aromatic-ring-hydroxylating dioxygenase-naphthalene 1,2-dioxygenase. Structure 6:571-586

Kim H-S, Cha SH, Suk HY, Kwon T-H, Woo J-H (2017) Complete genome sequence of indigo-producing bacterium Celeribacter $\mathrm{sp}$. strain TSPH2. Genome Announc 5:e01124-e 01117

Kim J, Lee P-G, Jung E-O, Kim B-G (2018) In vitro characterization of CYP102G4 from Streptomyces cattleya: a self-sufficient P450 naturally producing indigo. Biochim Biophys Acta, Proteins Proteomics 1866:60-67

Kosono S, Maeda M, Fuji F, Arai H, Kudo T (1997) Three of the seven bphC genes of Rhodococcus erythropolis TA421, isolated from a termite ecosystem, are located on an indigenous plasmid associated with biphenyl degradation. Appl Environ Microbiol 63:3282-3285

Kuhn D, Bühler B, Schmid A (2012) Production host selection for asymmetric styrene epoxidation: Escherichia coli vs. solvent-tolerant Pseudomonas. J Ind Microbiol Biotechnol 39:1125-1133

Kuo HH, Mauk AG (2012) Indole peroxygenase activity of indoleamine 2,3-dioxygenase. Proc Natl Acad Sci U S A 109:13966-13971

Leahy JG, Batchelor PJ, Morcomb SM (2003) Evolution of the soluble diiron monooxygenases. FEMS Microbiol Rev 27:449-479
Leveau JHJ, Gerards S (2008) Discovery of a bacterial gene cluster for catabolism of the plant hormone indole 3 -acetic acid. FEMS Microbiol Ecol 65:238-250

Li Q, Schwaneberg U, Fisher P, Schmid RD (2000) Directed evolution of the fatty-acid hydroxylase P450 BM-3 into an indole-hydroxylating catalyst. Chem Eur J 6:1531-1536

Lim HK, Chung EJ, Kim J-C, Choi GJ, Jang KS, Chung YR, Cho KY, Lee S-W (2005) Characterization of a forest soil metagenome clone that confers indirubin and indigo production on Escherichia coli. Appl Environ Microbiol 71:7768-7777

Lin G-H, Chen H-P, Huang J-H, Liu T-T, Lin T-K, Wang S-J, Tseng C-H, Shu H-Y (2012) Identification and characterization of an indigoproducing oxygenase involved in indole 3 -acetic acid utilization by Acinetobacter baumannii. Antonie Van Leeuwenhoek 101: 881-890

Lončar N, Fiorentini F, Bailleul G, Savino S, Romero E, Mattevi A, Fraaije MW (2019) Characterization of a thermostable flavincontaining monooxygenase from Nitrincola lacisaponensis (NiFMO). Appl Microbiol Biotechnol 103:1755-1764

Ma Q, Zhang X, Qu Y (2018) Biodegradation and biotransformation of indole: advances and perspectives. Front Microbiol 9:2625

Martínez AT, Ruiz-Dueñas FJ, Camarero S, Serrano A, Linde D, Lund H, Vind J, Tovborg M, Herold-Majumdar OM, Hofrichter M, Liers C, Ullrich R, Scheibner K, Sannia G, Piscitelli A, Pezzella C, Sener ME, K1lıç S, van Berkel WJH, Guallar V, Lucas MF, Zuhse R, Ludwig R, Hollmann F, Fernández-Fueyo E, Record E, Faulds CB, Tortajada M, Winckelmann I, Rasmussen J-A, Gelo-Pujic M, Gutiérrez A, Del Río JC, Rencoret J, Alcalde M (2017) Oxidoreductases on their way to industrial biotransformations. Biotechnol Adv 35:815-831

McClay K, Boss C, Keresztes I, Steffan RJ (2005) Mutations of toluene4-monooxygenase that alter regiospecificity of indole oxidation and lead to production of novel indigoid pigments. Appl Environ Microbiol 71:5476-5483

Mercadal JPR, Isaac P, Siñeriz F, Ferrero MA (2010) Indigo production by Pseudomonas sp. J26, a marine naphthalene-degrading strain. J Basic Microbiol 50:290-293

Meyer A, Würsten M, Schmid A, Kohler H-PE, Witholt B (2002) Hydroxylation of indole by laboratory-evolved 2-hydroxybiphenyl 3-monooxygenase. J Biol Chem 277:34161-34167

Murdock D, Ensley BD, Serdar C, Thalen M (1993) Construction of metabolic operons catalyzing the de novo biosynthesis of indigo in Escherichia coli. Biotechnology (NY) 11:381-386

Nagayama H, Sugawara T, Endo R, Ono A, Kato H, Ohtsubo Y, Nagata Y, Tsuda M (2015) Isolation of oxygenase genes for indigo-forming activity from an artificially polluted soil metagenome by functional screening using Pseudomonas putida strains as hosts. Appl Microbiol Biotechnol 99:4453-4470

Nordlund I, Powlowski J, Shingler V (1990) Complete nucleotide sequence and polypeptide analysis of multicomponent phenol hydroxylase from Pseudomonas sp. strain CF600. J Bacteriol 172:68266833

O’Connor KE, Dobson AD, Hartmans S (1997) Indigo formation by microorganisms expressing styrene monooxygenase activity. Appl Environ Microbiol 63:4287-4291

O'Connor KE, Hartmans S (1998) Indigo formation by aromatic hydrocarbon-degrading bacteria. Biotechnol Lett 20:219-223

Orru R, Dudek HM, Martinoli C, Torres Pazmiño DE, Royant A, Weik M, Fraaije MW, Mattevi A (2011) Snapshots of enzymatic BaeyerVilliger catalysis: oxygen activation and intermediate stabilization. J Biol Chem 286:29284-29291

Panke S, Witholt B, Schmid A, Wubbolts MG (1998) Towards a biocatalyst for (S)-styrene oxide production: characterization of the styrene degradation pathway of Pseudomonas sp. strain VLB120. Appl Environ Microbiol 64:2032-2043 
Parales RE, Resnick SM, Yu C-L, Boyd DR, Sharma ND, Gibson DT (2000) Regioselectivity and enantioselectivity of naphthalene dioxygenase during arene cis-dihydroxylation: control by phenylalanine 352 in the $\alpha$ subunit. J Bacteriol 182:5495-5504

Park J-B, Bühler B, Habicher T, Hauer B, Panke S, Witholt B, Schmid A (2006) The efficiency of recombinant Escherichia coli as biocatalyst for stereospecific epoxidation. Biotechnol Bioeng 95:501-512

Pathak H, Madamwar D (2010) Biosynthesis of indigo dye by newly isolated naphthalene-degrading strain Pseudomonas sp. HOB1 and its application in dyeing cotton fabric. Appl Biochem Biotechnol 160:1616-1626

Pazmiño DET, Snajdrova R, Rial DV, Mihovilovic MD, Fraaije MW (2007) Altering the substrate specificity and enantioselectivity of phenylacetone monooxygenase by structure-inspired enzyme redesign. Advanced Synthesis \& Catalysis 349:1361-1368

Qu Y, Pi W, Ma F, Zhou J, Zhang X (2010) Influence and optimization of growth substrates on indigo formation by a novel isolate Acinetobacter sp. PP-2. Bioresour Technol 101:4527-4532

Qu Y, Shi S, Zhou H, Ma Q, Li X, Zhang X, Zhou J (2012a) Characterization of a novel phenol hydroxylase in indoles biotransformation from a strain Arthrobacter sp. W1. PLoS One 7:e44313

Qu Y, Zhang X, Ma Q, Ma F, Zhang Q, Li X, Zhou H, Zhou J (2012b) Indigo biosynthesis by Comamonas sp. MQ. Biotechnol Lett 34: 353-357

Rebelo SLH, Linhares M, Simões MMQ, Silva AMS, Neves MGPMS, Cavaleiro JAS, Freire C (2014) Indigo dye production by enzymatic mimicking based on an iron(III)porphyrin. J Catal 315:33-40

Rioz-Martínez A, Kopacz M, de Gonzalo G, Torres Pazmiño DE, Gotor V, Fraaije MW (2011) Exploring the biocatalytic scope of a bacterial flavin-containing monooxygenase. Org Biomol Chem 9:1337-1341

Sadauskas M, Vaitekūnas J, Gasparavičiūtė R, Meškys R (2017) Indole biodegradation in Acinetobacter sp. strain O153: genetic and biochemical characterization. Appl Environ Microbiol 83:e01453e01417

Singh A, Singh Chauhan N, Thulasiram HV, Taneja V, Sharma R (2010) Identification of two flavin monooxygenases from an effluent treatment plant sludge metagenomic library. Bioresour Technol 101: $8481-8484$
Singleton DR, Hu J, Aitken MD (2012) Heterologous expression of polycyclic aromatic hydrocarbon ring-hydroxylating dioxygenase genes from a novel pyrene-degrading betaproteobacterium. Appl Environ Microbiol 78:3552-3559

Splitstoser JC, Dillehay TD, Wouters J, Claro A (2016) Early prehispanic use of indigo blue in Peru. Sci Adv 2:e1501623

Stephens GM, Sidebotham JM, Mann NH, Dalton H (1989) Cloning and expression in Escherichia coli of the toluene dioxygenase gene from Pseudomonas putida NCIB11767. FEMS Microbiol Lett 57:295300

Thotsaporn K, Chenprakhon P, Sucharitakul J, Mattevi A, Chaiyen P (2011) Stabilization of C4a-hydroperoxyflavin in a twocomponent flavin-dependent monooxygenase is achieved through interactions at flavin N5 and C4a atoms. J Biol Chem 286:28170 28180

Tischler D, Eulberg D, Lakner S, Kaschabek SR, van Berkel WJ, Schlömann M (2009) Identification of a novel self-sufficient styrene monooxygenase from Rhodococcus opacus 1CP. J Bacteriol 191: 4996-5009

van Berkel WJH, Kamerbeek NM, Fraaije MW (2006) Flavoprotein monooxygenases, a diverse class of oxidative biocatalysts. J Biotechnol 124:670-689

van Hellemond EW, Janssen DB, Fraaije MW (2007) Discovery of a novel styrene monooxygenase originating from the metagenome. Appl Environ Microbiol 73:5832-5839

Woo HJ, Sanseverino J, Cox CD, Robinson KG, Sayler GS (2000) The measurement of toluene dioxygenase activity in biofilm culture of Pseudomonas putida F1. J Microbiol Methods 40:181-191

Yen KM, Karl MR, Blatt LM, Simon MJ, Winter RB, Fausset PR, Lu HS, Harcourt AA, Chen KK (1991) Cloning and characterization of a Pseudomonas mendocina KR1 gene cluster encoding toluene-4monooxygenase. J Bacteriol 173:5315-5327

Publisher's note Springer Nature remains neutral with regard to jurisdictional claims in published maps and institutional affiliations. 